\title{
An unfortunate (and inappropriate) gastric biopsy
}

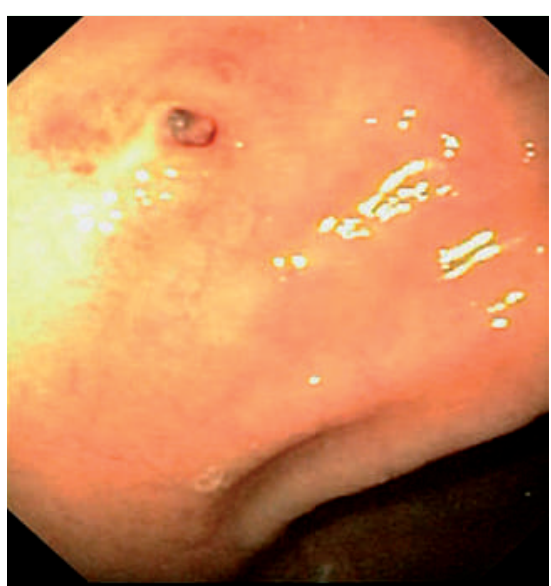

Fig. 1 Gastric erosion with an adherent clot.

A 66-year-old man presented to the emergency department of our hospital with hematemesis and melena of 10 hours' duration. On admission, the pulse rate was $81 \mathrm{bpm}$ and blood pressure was $100 / 50 \mathrm{~mm} \mathrm{Hg}$. The hematocrit was $22 \%$, the platelet count was $103000 / \mathrm{mm}^{3}$, and the international normalized ratio was 1.19 .

The patient had received a diagnosis of coronary heart disease 5 years earlier. He was treated with percutaneous coronary angioplasty, and took a daily aspirin dose of $100 \mathrm{mg}$. He had undergone screening endoscopy in another hospital 2 days before admission, because he had been diagnosed with hepatitis $C$ virus-related cirrhosis (Child-Pugh class A); upper gastrointestinal endoscopy was normal, and single-bite biopsies with conventional forceps were taken from normal-appearing gastric mucosa.
Early endoscopy revealed a gastric antral erosion with an adherent clot at the site of a previous single-bite biopsy ( $\bullet$ Fig. 1 ); three clips were placed onto the lesion. The patient received blood and platelet transfusions. Recovery was uneventful and the patient was discharged 5 days later.

Endoscopic biopsy is a procedure associated with a low risk of bleeding. Furthermore, there is insufficient evidence to indicate that concurrent use of aspirin increases the risk of bleeding related to endoscopic procedures. Aspirin does not prolong gastric bleeding time after gastric biopsies [1], and endoscopic procedures can be performed in patients taking aspirin [2]. However, procedure indication such as gastric biopsy should be carefully taken into account in patients with cumulative risk factors for bleeding, such as cirrhosis and low-dose aspirin use.

Endoscopy_UCTN_Code_CPL_1AH_2AB

\section{F. Armelao ${ }^{1}$, E. Tasini ${ }^{2}$}

1 Multizonale Gastroenterologia ed Endoscopia Digestiva, Ospedale S. Chiara, Trento, Italy

2 Multizonale Gastroenterologia ed Endoscopia Digestiva, Ospedale S. Maria del Carmine, Rovereto, Italy

\section{References}

1 O'Laughlin JC, Hoftiezer JW, Mahoney JP et al. Does aspirin prolong bleeding from gastric biopsies in man? Gastrointest Endosc 1981; 27: $1-5$

2 Eisen GM, Baron TH, Dominiz JA et al. Guideline on the management of anticoagulation and antiplatelet therapy for endoscopic procedures. Gastroentest Endosc 2002; 55 $775-779$
Bibliography

DOI $10.1055 / \mathrm{s}-2007-966964$

Endoscopy 2008; 40: E27

(c) Georg Thieme Verlag KG Stuttgart · New York . ISSN 0013-726X

Corresponding author

F. Armelao, MD

U.O. Multizonale Gastroenterologia ed

Endoscopia Digestiva

Ospedale S. Chiara

Largo Medaglie d'Oro

Trento

APSS

Italy

Fax: +39-461-903446

Franco.Armelao@apss.tn.it 